\title{
Validating MODIS above-cloud aerosol optical depth retrieved from "color ratio" algorithm using direct measurements made by NASA's airborne AATS and 4STAR sensors
}

\author{
Hiren Jethva ${ }^{1,2}$, Omar Torres ${ }^{2}$, Lorraine Remer ${ }^{3}$, Jens Redemann $^{4}$, John Livingston $^{5}$, Stephen Dunagan ${ }^{4}$, \\ Yohei Shinozuka ${ }^{6}$, Meloe Kacenelenbogen ${ }^{6}$, Michal Segal Rosenheimer ${ }^{6}$, and Rob Spurr ${ }^{7}$ \\ ${ }^{1}$ Universities Space Research Association, Goddard Earth Sciences Technology and Research (GESTAR), \\ Columbia, MD 21044, USA \\ ${ }^{2}$ Earth Science Division, Atmospheric Chemistry and Dynamics Laboratory, NASA Goddard Space Flight \\ Center, Greenbelt, MD 20771, USA \\ ${ }^{3}$ Joint Center for Earth Systems Technology, University of Maryland, Baltimore County, Baltimore, MD 21250, USA \\ ${ }^{4}$ Earth Science Division, NASA Ames Research Center, Moffett Field, CA 94035, USA \\ ${ }^{5}$ SRI International, Menlo Park, CA 94025, USA \\ ${ }^{6}$ Bay Area Environmental Research Institute, NASA Ames Research Center, Moffett Field, CA 94035, USA \\ ${ }^{7}$ RT Solutions, Cambridge, MA 02138, USA
}

Correspondence to: Hiren Jethva (hiren.t.jethva@nasa.gov)

Received: 23 May 2016 - Published in Atmos. Meas. Tech. Discuss.: 22 June 2016

Revised: 19 September 2016 - Accepted: 21 September 2016 - Published: 14 October 2016

\begin{abstract}
We present the validation analysis of above-cloud aerosol optical depth (ACAOD) retrieved from the "color ratio" method applied to MODIS cloudy-sky reflectance measurements using the limited direct measurements made by NASA's airborne Ames Airborne Tracking Sunphotometer (AATS) and Spectrometer for Sky-Scanning, Sun-Tracking Atmospheric Research (4STAR) sensors. A thorough search of the airborne database collection revealed a total of five significant events in which an airborne sun photometer, coincident with the MODIS overpass, observed partially absorbing aerosols emitted from agricultural biomass burning, dust, and wildfires over a low-level cloud deck during SAFARI-2000, ACE-ASIA 2001, and SEAC4RS 2013 campaigns, respectively. The co-located satellite-airborne matchups revealed a good agreement (root-mean-square difference $<0.1$ ), with most matchups falling within the estimated uncertainties associated the MODIS retrievals (about -10 to $+50 \%$ ). The co-retrieved cloud optical depth was comparable to that of the MODIS operational cloud product for ACE-ASIA and SEAC4RS, however, higher by $30-50 \%$ for the SAFARI2000 case study. The reason for this discrepancy could be attributed to the distinct aerosol optical properties encoun-
\end{abstract}

tered during respective campaigns. A brief discussion on the sources of uncertainty in the satellite-based ACAOD retrieval and co-location procedure is presented. Field experiments dedicated to making direct measurements of aerosols above cloud are needed for the extensive validation of satellitebased retrievals.

\section{Introduction}

Aerosol-cloud interaction continues to be one of the leading uncertain components of climate models, primarily due to the lack of an adequate knowledge of the complex microphysical and radiative processes associated with the aerosol-cloud system (Stocker et al., 2013). One important aspect of the problem is when aerosol and clouds are found in the same atmospheric column, for instance, such as carbonaceous particles generated from biomass burning and/or wind-blown dust overlay low-level cloud decks. Contrary to the cloudfree scenario over the dark surface, for which these aerosols are known to produce a net cooling effect (negative radiative forcing) on climate, the overlapping situation of absorbing 
aerosols over cloud can potentially exert a significant level of atmospheric absorption, and it produces a positive radiative forcing at top of atmosphere (TOA; Keil and Haywood, 2003; Chand et al., 2009). The magnitude of direct radiative effects of aerosols above cloud depends directly on the aerosol loading, the microphysical-optical properties of the aerosol layer and the underlying cloud deck (Meyer et al., 2013), as well as the geometric cloud fraction (Chand et al., 2009). The resultant aerosol-driven atmospheric heating can have a great influence on the atmospheric stability, cloud formation and lifetime, and the hydrological cycle.

In the past few years, the development of several independent algorithms that quantify aerosol loading above cloud from satellite-based active as well passive measurements has been a major breakthrough in the fields of aerosol and cloud remote sensing. These algorithms have shown the potential to retrieve quantitative information on aerosol loading above cloud using measurements from different A-train sensors including CALIOP/CALIPSO (Hu et al., 2007; Chand et al., 2008), Parasol/POLDER (Waquet et al., 2009, 2013; Peers et al., 2015), Aura/OMI (Torres et al., 2012), and Terra-Aqua/MODIS (Jethva et al., 2013; Meyer et al., 2015; Sayer et al., 2016). Of particular interest in the present paper is the "color ratio" (CR) technique that retrieves abovecloud aerosol optical depth (ACAOD) and aerosol-corrected cloud optical depth (COD), simultaneously, using OMI and MODIS observations independently. The technique is based physically on the unambiguous reduction of the ultraviolet (UV), visible (VIS), and near-infrared (NIR) radiation reaching the top of atmosphere, due to enhanced particle absorption above cloud. The effects of aerosol absorption have a spectral signature, in which the absorption strength is found to be stronger at shorter wavelengths than at longer. This produces a strong color effect in the two-channel measurements, hence, the name color ratio method. This technique was originally developed and successfully demonstrated using OMI's near-UV measurements (354 and $388 \mathrm{~nm}$; Torres et al., 2012); it was subsequently extended to the VIS-NIR measurements (470-860 $\mathrm{nm}$ ) made by MODIS (Jethva et al., 2013).

Although the unprecedented quantitative information on aerosol loading above cloud is now available from A-train sensors, an important question remains: how do we validate the satellite retrievals of ACAOD? Unlike the validation of cloud-free aerosol retrievals from satellites, for which ample ground-based measurements are available, validation of ACAOD is a challenging task primarily due to the lack of adequate direct measurements of aerosols in cloudy skies, specifically of aerosols above cloud. The availability of research-level retrievals of ACAOD from multiple sensors on the A-train satellite constellation offers an opportunity to intercompare aerosol loading derived using independent techniques applied to different sensors. Jethva et al. (2014) carried out an inter-sensor comparison analysis using retrievals from MODIS, CALIOP, POLDER, and OMI for the two scenarios of smoke above cloud observed over the southeastern Atlantic Ocean; they found that A-train sensors agree with each other to within an AOD difference of less than 0.2 over homogeneous opaque cloud fields. Despite the fact that each method is designed independently and relies on different types of measurements from different sensors, the overall close agreement between them was an encouraging result. However, the inter-sensor comparison analysis does not constitute a validation exercise; instead the level of agreement can be interpreted as a measure of consistency (or lack thereof) in the retrieval.

While ground-based measurements such as those from AERONET (Aerosol Robotic Network) cannot be directly helpful in our situation, airborne measurements taken when the aircraft is flying above cloud seem to be the only means to validate the above-cloud aerosol retrievals. In pursuit of finding the right dataset, we have looked at the data archive of past field campaigns with a focus on aircraft-based direct measurements of AOD. We found that the airborne measurements made by NASA's 6-14-channel Ames Airborne Tracking Sunphotometer (AATS-6, -14) and their next generation sensor Spectrometer for Sky-Scanning, Sun-Tracking Atmospheric Research (4STAR) provide a valuable database for validating the satellite retrieval of ACAOD. The High Spectral Resolution Lidar (HSRL) is another instrument which can measure the vertical profile of particulate extinction without assuming a lidar ratio, and thus can provide a direct measure of AOD above cloud provided that the HSRL flies above the aerosol layer. Kacenelenbogen et al. (2014) have used HSRL measurements collected during different flights over North America for evaluating the CALIOP standard product of AOD above cloud.

In this paper, we present the validation analysis of ACAOD retrieved from the MODIS sensor using cloudy-sky airborne measurements of AOD made by AATS and 4STAR. We mention here that we were unable to perform a validation analysis of OMI ACAOD retrieval due to two reasons: (1) four out of the five events of aerosols above clouds observed by AATS occurred prior to the launch of OMI in 2004, and (2) an event of wildfire smoke aerosols above clouds measured by 4STAR on 6 August 2013 was missed by OMI due to row anomaly contamination encountered during post-2008 operation. The rest of the paper is organized as follows: Sect. 2 introduces datasets and the co-location approach; results of satellite vs. airborne measurements are presented in Sect. 3; and a discussion of the uncertainties and future scope of validation study is presented in Sect. 4.

\section{Datasets}

\subsection{Ames Airborne Tracking Sunphotometer (AATS)}

The 6- and 14-channel AATS developed by the NASA Ames research group (Russell et al., 1993; Redemann et al., 2003) 
measures the transmission of the solar beam in distinct spectral bands from near-UV to VIS to NIR and subsequently calculates the columnar aerosol optical depths (AODs). AATS's azimuth and elevation motors, which are controlled with a quadrant differential photodiode sun sensor, rotate a tracking head that locks the detector normal to the solar beam, and thus provides the direct measurements of solar transmission. The tracking head can be mounted outside the aircraft body to minimize blockages by aircraft structures; this enables direct measurements of AOD during flight operation at different altitudes. Further information on AATS and its next generation sensor 4STAR can be found in the above papers as well as at the web link: http://geo.arc.nasa.gov/sgg/ AATS-website/.

AATS has been operated in several field campaigns, starting as early as July 1996 during the Tropospheric Aerosol Radiative Forcing Observational Experiment (TARFOX), and including the second Aerosol Characterization Experiment (ACE-2), South African Regional Science Initiative (SAFARI) 2000 (Schmid et al., 2003b), Asian Pacific Regional Aerosol Characterization Experiment (ACE-Asia; Schmid et al., 2003a; Redemann et al., 2003), and Chesapeake Lighthouse and Aircraft Measurements for Satellites (CLAMS; Redemann et al., 2001). More recently, the Ames Sunphotometer/Satellite team has developed an advanced instrument called Spectrometers for Sky-Scanning, SunTracking Atmospheric Research (4STAR; Dunagan et al., 2013; Shinozuka et al., 2013; Segal-Rosenheimer et al., 2014), which extends the capabilities of AATS by adding a sky-scanning mechanism that enables the retrieval of complex refractive index, shape, and aerosol size distribution. Furthermore, an additional use of spectrometer can make measurements of trace gases (e.g., $\mathrm{NO}_{2}$ ) in order to enhance the accuracy of aerosol measurements via improved aerosol-gas separation. Recently, the 4STAR instrument participated in the Studies of Emissions, Atmospheric Composition, Clouds and Climate Coupling by Regional Surveys (SEAC4RS) experiment conducted during August 2013 over the southern and western United States. The first flight of SEAC4RS covered parts of Oregon, California, and the neighboring Pacific Ocean, and measured the properties of aerosols and trace gases emitted from wildfires over the region.

A thorough search of the AATS and 4STAR datasets has revealed a total of five significant events of aerosols above cloud observed during different field campaigns that are also co-located with the MODIS overpasses. These include an event with carbonaceous aerosols overlaying a marine boundary layer stratocumulus cloud deck over the southeastern Atlantic Ocean on 13 September 2000 (AATS Flight no. 1837; Schmid et al., 2003a), three events of dust plumes above clouds observed during ACE-ASIA in 2001 (20, 30 April, and 4 May, Redemann et al., 2003) over the Sea of Japan and the East China Sea, and a wildfire smoke event observed on 6 August 2013 over the Pacific Ocean during the first test flight just before the main phase of SEAC4RS 2013 began over the southern United States. The absolute error in the aircraft-mounted AATS and 4STAR measurements of AOD for these flights was mostly in the range 0.02 to 0.03 , with the maximum error reaching up to 0.05 for certain measurements. Owing to its high accuracy relative to the expected uncertainty in the satellite retrieval, we treat aircraft measurements as truth for validating satellite retrievals of ACAOD. We use only quality-controlled, cloud-sky AOD data collected by both airborne sensors in the present analysis.

\subsection{MODIS}

The presence of an absorbing aerosol layer above cloud reduces the TOA reflectance as well as color ratio between VIS and NIR wavelengths. The general CR technique developed by Jethva et al. (2013) exploits this unambiguous signal and uses reflectance at two channels (470 and $860 \mathrm{~nm}$ ) to retrieve ACAOD and aerosol-corrected COD, simultaneously. The CR technique was originally developed for retrieving ACAOD using OMI's near-UV observations (Torres et al., 2012); however, it was then extended to MODIS visible/NIR observations. The method requires MODIS TOA reflectances (MOD/MYD021KM), geolocation data (MOD/MYD03), and the MODIS cloud product (MOD/MYD06) - all three datasets correspond to $1 \mathrm{~km}$ spatial resolution. In the present analysis, we use MODIS Collection 006 products obtained from http://ladsweb.nascom. nasa.gov/data/. The aerosol optical and microphysical models required to generate lookup tables (LUTs) of simulated TOA reflectances were derived from the multi-year statistics of the AERONET cloud-free Level 2 direct measurements and inversions carried out at Mongu $\left(15^{\circ} \mathrm{S}, 23^{\circ} \mathrm{E}\right)$, Zambia, in southern Africa, Noto $\left(37.33^{\circ} \mathrm{N}, 137.14^{\circ} \mathrm{E}\right)$ in Japan, and HJAndrews $\left(44.24^{\circ} \mathrm{N}, 122.22^{\circ} \mathrm{W}\right)$ in California, for representing aerosol properties for the SAFARI-2000, ACE-ASIA, and SEAC4RS campaigns, respectively. Table 1 lists the assumed aerosol microphysical and optical properties derived from AERONET dataset. We employ the VLIDORT V2.6 polarized radiative transfer model (Spurr, 2006) for the simulation of LUT reflectances. The vertical profile of aerosols is assumed to follow a Gaussian distribution with the peak at height $3 \mathrm{~km}$; a cloud layer was placed between 1 and $1.5 \mathrm{~km}$ - both are generally consistent with the climatological vertical structure of aerosols and clouds observed by the CALIOP lidar over the three regions. The retrieved ACAOD at $470 / 860 \mathrm{~nm}$ was converted to its value at $500 \mathrm{~nm}$ according to the spectral extinction assumed in the selected aerosol models.

\subsection{Co-location of satellite-airborne sensors}

In contrast to the validation of cloud-free AOD retrieved from satellites, in which columnar retrievals are compared 
Table 1. Aerosol properties assumed in the simulation of TOA reflectance lookup tables for different events of aerosols above clouds discussed in the text. The assumed microphysical and optical properties were derived from multi-year AERONET measurements at representative sites Mongu $\left(15^{\circ} \mathrm{S}, 23^{\circ} \mathrm{E}\right)$, Zambia, in southern Africa, Noto $\left(37.33^{\circ} \mathrm{N}, 137.14^{\circ} \mathrm{E}\right)$ in Japan, and HJAndrews $\left(44.24^{\circ} \mathrm{N}, 122.22^{\circ} \mathrm{W}\right)$. Notation: $R_{\mu} / R_{\sigma}$ : mean/standard deviation radius of the Gaussian particle size distribution; $i_{\text {real }} / i_{\text {img }}:$ real/imaginary parts of the refractive index; SSA: aerosol single-scattering albedo.

\begin{tabular}{lcc|cc|cc|cc}
\hline & \multicolumn{2}{c|}{$R_{\mu} / R_{\sigma}$} & \multicolumn{2}{c|}{$i_{\text {real }}$} & \multicolumn{2}{c|}{$i_{\text {img }}$} & \multicolumn{2}{c}{ SSA } \\
\cline { 2 - 9 } AERONET sites & Fine & Coarse & $470 \mathrm{~nm}$ & $860 \mathrm{~nm}$ & $470 \mathrm{~nm}$ & $860 \mathrm{~nm}$ & $470 \mathrm{~nm}$ & $860 \mathrm{~nm}$ \\
\hline Mongu, Zambia & $0.0898 / 1.4896$ & $0.9444 / 1.9326$ & 1.50 & 1.50 & 0.0262 & 0.0248 & 0.85 & 0.79 \\
Jul-Aug-Sep 1995-2009 & & & & & & & & \\
Noto, Japan & $0.0886 / 1.5740$ & $0.6036 / 1.9272$ & 1.50 & 1.50 & 0.0092 & 0.0060 & 0.91 & 0.92 \\
Apr 2001-2013 & & & & & & & & \\
HJAndrews, CA, USA & $0.0803 / 1.5660$ & $0.8381 / 1.9778$ & 1.60 & 1.56 & 0.0145 & 0.0165 & 0.92 & 0.86 \\
Aug 1994-2011 & & & & & & & & \\
\hline
\end{tabular}

against ground-based measurements following a static spatiotemporal approach (Ichoku et al., 2002), validating abovecloud aerosol retrieval using airborne data poses different challenges. First, the airborne sensor is on a moving platform both in horizontal and vertical directions; it therefore needs to be continuously tracked for the co-location with nearby satellite retrieval. Second, it makes measurements at different altitudes along the aircraft trajectory, which more often than not, do not represent the same atmospheric column above the cloud that is seen from the satellite. In order to make the satellite-airborne measurements comparable, therefore, either the airborne measurements need to be adjusted all the way down to the cloud top, or else the satellite retrieval must be scaled to the aircraft altitude. To address these issues, we adopt a dynamic spatiotemporal approach in which the satellite pixels with valid AOD retrieval are first co-located within an area of $0.5^{\circ} \times 0.5^{\circ}$ centered at aircraft's spatial location. Although the selected area of spatial co-location between satellite and aircraft was large, most matchups were found within a 0.15 to $0.25^{\circ}$ square region for all five cases. In fact, for the SAFARI-2000 case study we found most matchups within a $0.10^{\circ}$ square region of the aircraft path. The reason for selecting a larger box area was to collect as many MODIS retrievals as possible for the comparison. Note that it is not always necessary that MODIS retrieves ACAOD for all cloudy pixels; some pixels might not have been retrieved due to an out-of-domain issue, in which the observations fall outside the range of lookup table radiances. The airborne AODs are spatially averaged for the consecutive five measurements in order to match with the spatial scale of MODIS retrieval $(1 \mathrm{~km})$. The AOD measured by the airborne sensor then is scaled to the area-averaged satelliteretrieved cloud top pressure using information on the vertical distribution of AOD measured during the same flight. This is done by deriving a polynomial of altitude-dependent ratio of $\mathrm{AOD}$ and subsequently using it to estimate columnar AOD at the retrieved cloud top pressure as follows:

$$
\begin{aligned}
& F=C_{0}+C_{1} \times P_{\text {meas }}+C_{2} \times P_{\text {meas }}^{2} \\
& +C_{3} \times P_{\text {meas }}^{3}+C_{4} \times P_{\text {meas }}^{4} \\
& \mathrm{AOD}_{\mathrm{CTP}}=\mathrm{AOD}_{P_{\text {meas }}} \times F \times(\mathrm{CTP} / 900 .),
\end{aligned}
$$

where $C_{0}, C_{1}, C_{2}, C_{3}$, and $C_{4}$ are the coefficients of the polynomial, $P_{\text {meas }}$ is the pressure level of measured AOD, and $F$ is the factor or ratio of AOD at $900 \mathrm{hPa}$ to AOD at the measured pressure level. The scaled AOD ( $\left.\mathrm{AOD}_{\mathrm{CTP}}\right)$ is then calculated using measured AOD at a particular pressure level $\left(\mathrm{AOD}_{P_{\text {meas }}}\right)$, factor $F$, and measured cloud top pressure (CTP) as given in Eq. (2). The procedure is demonstrated in Fig. 1, which shows the vertical profile of above-aircraft AOD (left) and corresponding ratio of AOD (right) measured by AATS-14 during the SAFARI-2000 flight UW1837, which flew on 13 September 2000. Note that the profiling of AOD during each flight was carried out in a particular location, and in the process of scaling it is assumed that the relative vertical distribution of AOD quantified as factor $F$ does not change during the entire course of the flight. Finally, the area-averaged AOD measurements from the airborne sensor and MODIS are compared. The advantage of scaling the suborbital measurements is that both the columnar AOD and the vertical profile of AOD are measured directly, and are therefore considered to be the most reliable in terms of accuracy.

\section{Results}

Figure 2 (top) shows the true-color RGB images captured by Terra/MODIS for different events over three regions where airborne sun photometer AOD measurements were made above cloud. Superimposed on these images are the colorcoded trajectories of the aircraft where the colors present discrete values of the measured AOD $(500 \mathrm{~nm})$. The spatial distribution of ACAOD retrieved from the CR algorithm for these events is shown in the bottom of Fig. 2. MODIS retrievals were restricted to pixels with $\mathrm{CR}<1.05$ 


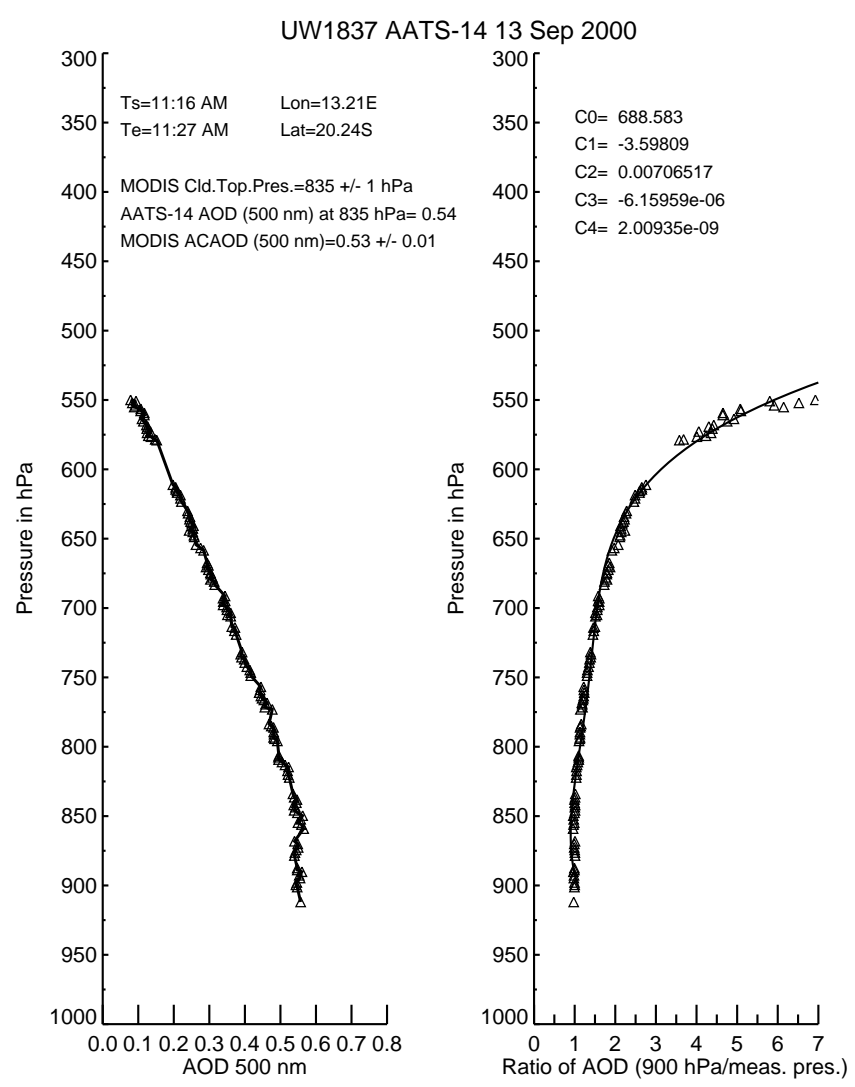

Figure 1. Left: vertical profile of above-aircraft columnar AOD $(500 \mathrm{~nm})$ measured by AATS-14 during SAFARI-2000 flight UW1837, which flew on 13 September 2000 over Walvis Bay. Right: altitude dependence of ratio of AOD at $900 \mathrm{hPa}$ to AOD at different pressure levels measured during the same flight.

and COD $>3$ for better retrieval accuracy (Jethva et al., 2013). Note that the color scale for AOD for both airborne and satellite retrievals is identical. For the SAFARI-2000 event, both the airborne AATS-14 and the MODIS obtain values of ACAOD mostly in the range $0.5-0.6$ over the areas north of Walvis Bay, Namibia. MODIS retrievals also show a northward gradient (positive) in AOD, which is likely due to the northern region's proximity to the overland source of agricultural burning. For the case of 20 April 2001 of ACEASIA, MODIS retrieves a gradient in AOD along the northern coast of Japan. For the wildfire event observed on $6 \mathrm{Au}-$ gust 2013 during the SEAC4RS campaign, MODIS retrieves higher values of AOD off the coast of California/Oregon and lower AODs away from the coast.

Figure 3 (left) shows the color-coded scatter plot of ACAOD $(500 \mathrm{~nm})$ retrieved from MODIS ( $y$ axis) vs. that measured by the airborne AATS/4STAR sensor ( $x$ axis) for the five events of aerosols above clouds. Solid lines represent the expected error envelope associated with the MODIS retrievals at an actual COD of 10 (Jethva et al., 2013). The statistical summary of the MODIS vs. airborne ACAOD com- parison is given in Table 2. Among the five events, we find the most extensive matchups accompanied with best comparison for the SAFARI-2000 case of biomass burning aerosols above cloud; this is followed by the dust-above-cloud events observed during ACE-ASIA 2001 and lastly, the wildfiregenerated carbonaceous aerosols above cloud observed over the Pacific Ocean during SEAC4RS 2013.

The presence of absorbing aerosols above cloud obstructs the light reflected by the cloud top, and thus reduces upwelling UV, VIS, and NIR radiation reaching the TOA. Therefore, cloud retrievals of COD derived from passive sensors such as MODIS are expected to be biased low if absorbing aerosols are not accounted for in the inversion (Wilcox et al., 2009; Jethva et al., 2013; Meyer et al., 2015). Among several techniques developed to characterize aerosols above cloud, the CR method and the multispectral technique developed by Meyer et al. (2015) retrieve ACAOD and COD fields simultaneously. A comparison plot of COD retrieved by the CR algorithm and that of the MODIS C006 operational product is shown in Fig. 3 (right). We find that the CODs retrieved from the CR algorithm are consistently higher by 30-50\% than those retrieved from MODIS C006 for the SAFARI-2000 case. For the aerosol events of ACE-ASIA and SEAC4RS, CODs retrieved from both algorithms are found to be comparable in magnitude. One of the possible reasons for the observed discrepancies between different cases could be the distinct aerosol properties that affect cloud retrieval differently. The negative bias in COD retrieval is directly proportional to the strength of absorption above cloud, which is expressed as the aerosol absorption optical depth $(\mathrm{AAOD}=\mathrm{AOD} \times(1-\mathrm{SSA}))$. Long-term groundbased aerosol inversions made by AERONET over respective regions show that carbonaceous aerosols generated from biomass burning over southern Africa are strongly absorbing, with a single-scattering albedo (SSA) of $\sim 0.85$ and $\sim 0.79$ at 470 and $860 \mathrm{~nm}$, respectively, whereas aerosols encountered over northeastern Asia and western United States during months of the events studied here exhibit relatively weaker absorption capacity (SSA at $860 \mathrm{~nm} \sim 0.92$ and $\sim 0.86$ ). For the SAFARI-2000 case, strong absorption by aerosols above cloud resulted from relatively larger AOD, and lower SSA introduces negative bias in the MODIS standard retrieval of COD, as compared with the retrieval by the CR technique that accounts for the aerosol absorption in the cloud retrieval. For the other four cases, it appears that a relatively lower amount of aerosol loading accompanied by higher SSA results in weaker aerosol absorption, which is likely to be comparable to the back-scattering component, thereby making little to no difference in the cloud-reflected radiation measured at TOA and thus better agreement between the two independently retrieved cloud retrievals. Additionally, the departure of the assumed aerosol properties from the actual ones can also lead to errors in the COD retrieval. A sensitivity analysis presented in our previous paper, Jethva et al. (2013), suggests that an underestimated SSA of 0.03 in the 
Table 2. Statistical summary of the MODIS vs. airborne above-cloud AOD comparison.

\begin{tabular}{llcccc}
\hline Field campaign & Event date & $N$ & RMSD & $\begin{array}{c}\% \text { matchups within } \\
\text { predicted uncertainty } \\
\text { (Jethva et al., 2013) }\end{array}$ & $\Delta T$ \\
\hline SAFARI-2000 & 13 Sep 2000 & 122 & 0.052 & 99.18 & 30 min to 2 1/2 h \\
ACE-ASIA 2001 & 20,30 Apr, 4 May & 67 & 0.051 & 83.58 & 2 to 6h \\
SEAC4RS 2013 & 6 Aug 2013 & 34 & 0.100 & 50.00 & $T: 30$ min to 2h \\
& & T: 16 A: 18 & T: 0.103 A: 0.095 & T: 35.29\% A: 61.11\% & A: $2 \mathrm{~h}$ \\
\hline
\end{tabular}

$N$ : number of matchups. $\Delta T$ : time difference between satellite overpass and airborne measurements. RMSD: root-mean-square difference. T: Terra, A: Aqua.
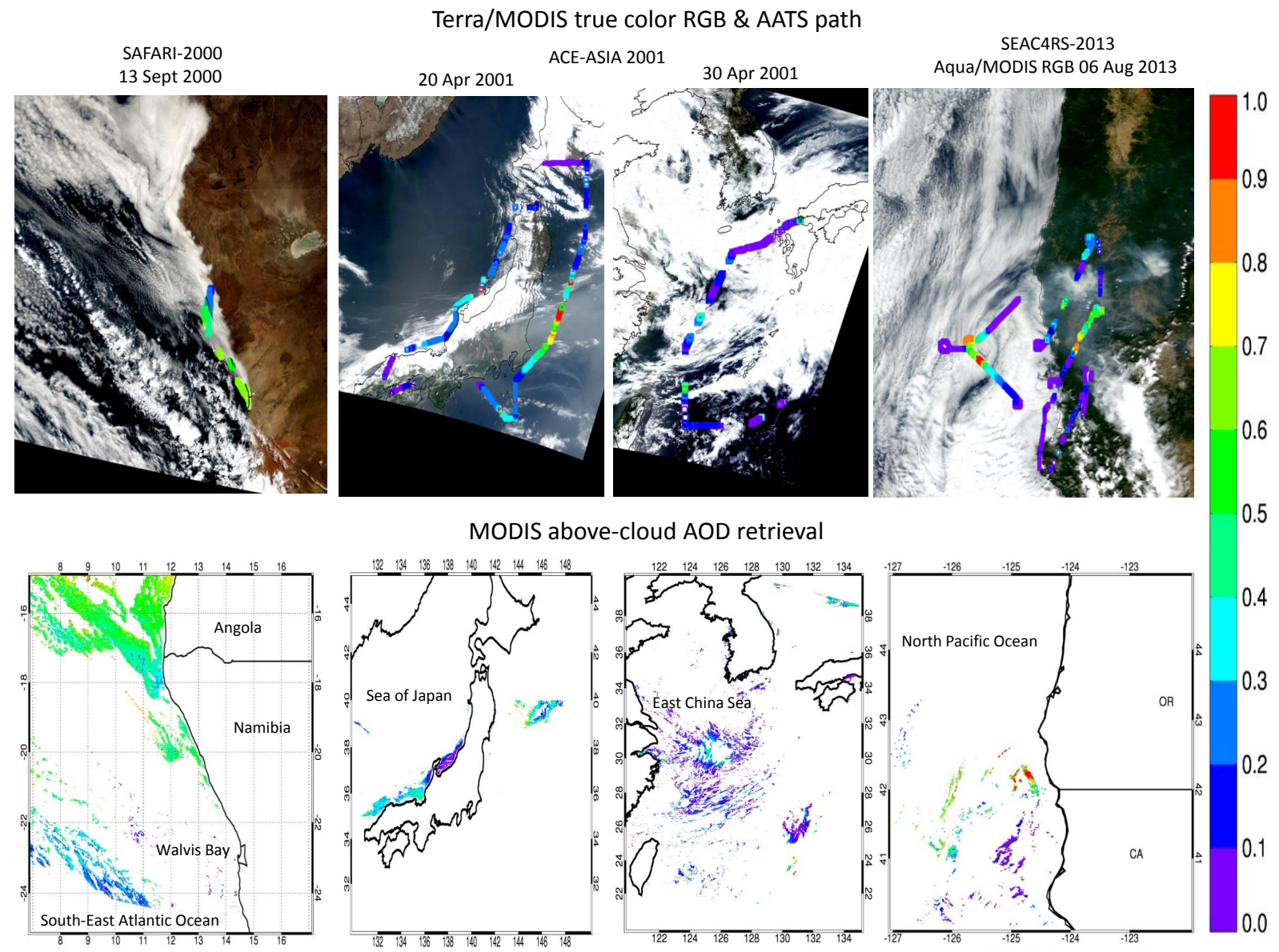

Figure 2. Top: true-color RGB images captured by MODIS superimposed with AOD ( $500 \mathrm{~nm})$ measured by AATS-6,-14/4STAR on 13 September 2000, 20, 30 April 2001, and 6 August 2013 during SAFARI-2000, ACE-ASIA 2001, and SEAC4RS 2013, respectively. Bottom: spatial distribution of above-cloud AOD $(500 \mathrm{~nm})$ retrieved from MODIS for the respective dates.

assumed SSA yields an error of -4 to $-9 \%$, whereas an overestimation in SSA by the same amount results in an error of about 8 (for ACAOD of 0.5) to $25 \%$ (for ACAOD of $1.0)$. Note that these are our speculations that demand further analysis supported by the airborne in situ measurements of SSA.

\section{Discussion and conclusion}

\subsection{Sources of uncertainties in ACAOD}

Although the satellite retrieval of ACAOD is found to be in good agreement with airborne measurements, some discrepancies remain. The $\mathrm{CR}$ algorithm makes assumptions about properties of aerosol and cloud in order to perform inversion from satellite observations. Two most important assumptions 

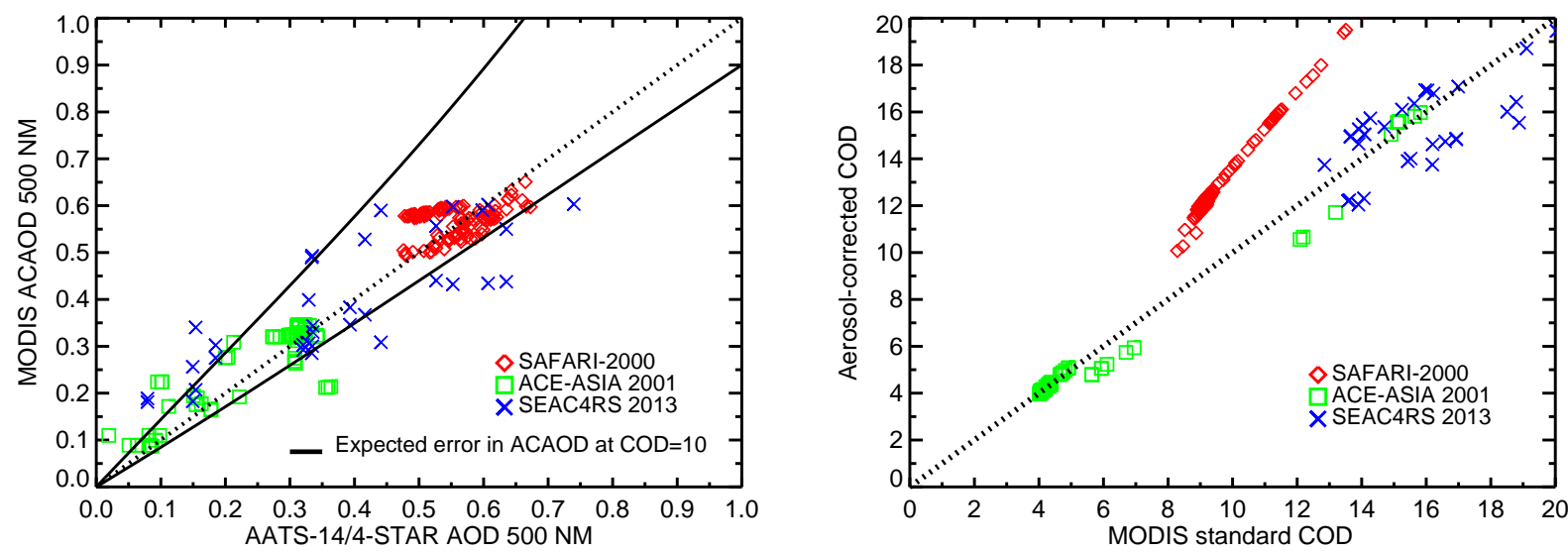

Figure 3. Left: scatter plot of above-cloud AOD retrieved from MODIS ( $y$ axis) and that measured by AATS-6,-14/4STAR ( $x$ axis) for the five events discussed in the text. Right: a comparison of aerosol-corrected COD retrieved from the CR algorithm with those provided by the MODIS standard algorithm (MOD/MYD06).

made in the algorithm are the value of the imaginary part of refractive index, which for a given particle size distribution can be expressed as SSA, and vertical profiles of clouds and aerosols. The theoretical uncertainty analysis adopted for the MODIS wavelengths suggests that, while an uncertainty of $\pm 1 \mathrm{~km}$ in the assumption of aerosol layer height results in errors of $15 \%$ or less in ACAOD, the retrievals are found to be more susceptible to the choice of aerosol model, particularly the SSA (Jethva et al., 2013). For an ACAOD $(500 \mathrm{~nm})$ of 1.0, an error of \pm 0.03 in the assumption of SSA can lead to an error of about $-10 /+50 \%$ in the ACAOD for an actual COD of 10. In a recent paper by Meyer et al. (2015), it is shown that the use of two distinct aerosol models, i.e., one derived from SAFARI-2000 in situ measurements (Haywood et al., 2003) and one adopted from the MODIS dark-target overland aerosol algorithm MOD04 (Levy et al., 2007), yield different magnitudes of MODIS-based ACAOD over the southeastern Atlantic Ocean. The two aerosol models differed mainly in terms of SSA, where the SAFARI-2000 measurements showed SSA of 0.92 and 0.89, and MOD04 aerosol model assumes SSA of 0.88 and 0.80 at 470 and $860 \mathrm{~nm}$ wavelengths respectively. Use of these two models resulted in a relative difference of about 30,40 , and $60 \%$ at an ACAOD of 1.0, 2.0, and 3.0, respectively. The reason for larger errors in ACAOD due to uncertainty in SSA could be following. For an opaque cloud $(\mathrm{COD}>10)$ with a fixed value of COD, the changes in TOA radiances due to aerosols are primarily governed by the aerosol absorption optical depth. Since AAOD is a product of AOD and aerosol co-albedo (1-SSA), a perturbation in SSA from the baseline value with a given fixed value of AAOD will alter the retrieval of ACAOD from its original value. Thus, an erroneous representation of SSA causes the algorithm to retrieve a different value of AOD in order to explain the observed radiation fields at TOA.
The absorption properties assumed in the aerosol models (Table 1) represent average conditions derived from longterm observations at AERONET sites in the respective regions. These values may vary in space and time, which depends on the type of source, mixing with other pollutants, humidity, and chemical transformation along transport; sometimes the properties also vary systematically (e.g., Eck et al., 2013). For instance, the SSA retrieved by AERONET at Mongu on and close to days around the case study of 13 September 2000 was about 0.89 at $470 \mathrm{~nm}$ and $0.83-0.86$ at $860 \mathrm{~nm}$, which is higher in magnitude compared to the climatological values assumed in the present analysis $(\mathrm{Ta}-$ ble 1). Similarly, for the ACE-Asia 2001 case studies (20, 30 April and 4 May) the AERONET site at Noto reports SSA in the range 0.87 to 0.94 at both wavelengths, whereas the averaged values of SSA assumed in this analysis fall in between this range. During the last few years, several techniques have been developed to characterize absorbing aerosols above clouds using NASA's A-train sensors. Efforts from different groups are underway to apply the respective algorithms on an operational and even near-real time basis. We recognize that it is not possible for an operational aerosol algorithm, be it for cloud-free or above-cloud situations, to characterize aerosol microphysical and optical properties for every pixel on a daily basis. For instance, NASA's operational cloud-free aerosol algorithms applied to MODIS, OMI, and MISR therefore rely on precalculated lookup tables derived using aerosol-type specific regional models derived from long-term record of ground-based observations in the respective regions. In view of the anticipated application of these research algorithms on an operational scale and realizing the non-feasibility of the dynamic characterization of aerosol properties, in the present analysis we adopted the climatological aerosol models based on the long-term AERONET observations. 
Besides algorithmic assumptions, the comparison of airborne measurements vs. satellite retrievals can also be affected by the effectiveness of co-location methodology. First, the time difference between the satellite overpass time and AATS/4STAR measurements ranges from $30 \mathrm{~min}$ to $4 \mathrm{~h}$ (Table 2), which is larger than the typical time window of 30 min adopted in the validation exercise of the clear-sky satellite products. Any changes in the aerosol and cloud fields between the time domain of airborne measurements and satellite retrievals will inevitably introduce a mismatch in the comparison. Second, the scaling procedure described in Sect. 2.3 relies on a single profile of AOD measured during respective fights and assumes its validity along the entire path of aircraft sortie. While the information on vertical structure of aerosols outside the region of profile measurements is not known, deviation from the assumed profile of AOD can also add uncertainty in the AOD scaled to the cloud top pressure. Third, the scaling of AOD involves the use of MODIS-retrieved cloud top pressure, which is uncertain to within $50 \mathrm{hPa}$ (Menzel et al., 2008). A sensitivity study for the SAFARI-2000 case in which the cloud top pressure was perturbed by \pm 50 and $\pm 100 \mathrm{hPa}$ from its retrieved values from MODIS resulted in the root-mean-square difference (MODIS minus AATS) of \pm 0.02 and \pm 0.05 , respectively. These magnitudes of error are comparable to the absolute error in the AATS measurements. The reason for low errors in AOD scaling for this case could be the fact that the AOD measured by AATS between 850 and $900 \mathrm{hPa}$ is almost similar, and the MODIS-retrieved cloud top pressure for the matchup points mostly falls in this range of pressure, making not much difference in the scaling even if cloud top pressure is perturbed by $\pm 100 \mathrm{hPa}$. It is possible that the uncertainty associated with the scaling of AOD would be larger than 0.05 if the signs of error in AOD measurements and cloud retrievals are both in the same direction (positive or negative), or even can partially cancel each other if the sign is in an opposite direction.

The main purpose of the validation exercise, such as presented in this paper, is to assess the accuracy of the satellitebased retrievals given the algorithmic assumptions about aerosol and cloud models. It is expected that using the "true" values of aerosol microphysical and optical properties for the present case studies will provide more accurate retrievals. However, we emphasize that despite the multi-year approach adopted here for developing aerosol models and inherent uncertainty in the co-location procedure, MODIS retrievals of ACAOD are in overall good agreement with the airborne direct measurements within the expected uncertainty limits. This by itself provides an indirect assessment of the assumptions made in the inversion process, which seem to be working reasonably well for the present case studies.

\subsection{Future validation activities}

The present paper has attempted to validate the satellite retrieval of ACAOD using a limited set of airborne sun photometer measurements. We emphasize here that this work is just the beginning of a continuing exercise of evaluating space-based characterization of aerosols above cloud. Past field campaigns focused on characterizing aerosol properties in cloud-free regions in order to evaluate and improve satellite-based retrievals, but this left vast cloudy areas unmonitored in terms of aerosol measurements. Now satellitebased remote sensing techniques using passive sensors are beginning to quantitatively retrieve aerosol loading above cloud over a large spatial domain; however validation of these retrievals will remain incomplete without the availability of adequate and accurate airborne measurements.

NASA's ORACLES (ObseRvations of Aerosols above CLouds and their intEractionS; https://espo.nasa.gov/ oracles) is an upcoming multi-year field experiment funded by the NASA Earth-Venture Suborbital Program. Beginning in July 2016, the ORACLES experiment intends to make detailed and accurate airborne remote sensing and in situ measurements of the key parameters that govern the cloud-aerosol interaction in the southeastern Atlantic Ocean. Owing to the huge abundance of lofted biomass burning aerosols over the semi-permanent marine boundary layer stratocumulus cloud deck, this region serves as a perfect natural laboratory to assess aerosol-cloud-radiation interactions. Note that this is an area with some of the largest inter-model differences in aerosol forcing assessments on the planet. The experiment will employ a suite of sensors including 4STAR and High Spectral Resolution Lidar (HSRL-2) on NASA's P-3B and ER-2 aircrafts, respectively. Both instruments are capable of making measurements of AOD above cloud, and are therefore relevant to the assessment of the equivalent satellite retrieval.

In parallel with ORACLES, the Cloud Aerosol Radiation Interactions and Forcing: Year 2016 (CLARIFY-2016) campaign with project partners from the UK Met Office and universities will also take place over the same region with deployment of airborne and surface-based instruments in conjunction with satellite observations of aerosols and clouds. Both of these planned high-profile experiments will deliver a wide range of direct and in situ observations of aerosol above clouds to provide a better process-level understanding of aerosol-cloud-radiation interactions over the SE Atlantic. Among the planned measurements, direct AOD and detailed optical and microphysical measurements of aerosols above cloud will be germane for validating and improving satellitebased retrievals. For instance, the microphysical models, in particular the imaginary part of refractive index and SSA assumed in the satellite-based inversion, pose the largest source of uncertainty in the retrieval. Observations from ORACLES and CLARIFY-2016 will challenge and improve these models for achieving better accuracy in the satellite retrieval. 
In addition to the validation activities, intercomparison of retrievals from A-train sensors should be carried out on various spatial and temporal scales and over distinct hot spot regions of the world, where the overlap of absorbing aerosols and cloud is observed frequently. This is needed to better understand the relative strengths and weaknesses of each sensor and to check the inter-consistency between them. Currently, all ACAOD retrievals are research-only algorithms, but we expect as these algorithms are better understood they could evolve into deliverable operational or semi-operational products on a global scale in the coming years. True validation exercises, such as the opportunities to compare retrievals with a high-quality airborne instrument as presented here, are essential components in providing the confidence needed towards moving algorithms into operations. A global above-cloud aerosol product, in conjunction with standard cloud-free aerosol products derived from satellites, will provide us an unprecedented all-sky aerosol distribution from space. This can substantially enhance our knowledge on how aerosols affect cloud radiative forcing and microphysical properties, and aerosol transport.

\section{Data availability}

The direct measurements of aerosol optical depth made by airborne AATS and 4STAR sunphotometers were accessed from http://geo.arc.nasa.gov/sgg/AATS-website.

MODIS Level 1 data were obtained from http://ladsweb. nascom.nasa.gov/data/.

MODIS above-cloud aerosol optical depth data were retrieved using a research-level stand-alone algorithm described in Jethva et al. (2013).

Acknowledgements. We acknowledge the support of the LAADS team for online availability of the MODIS dataset. We also extend our thanks to the principal investigators of AERONET sites for providing the data that were used to build the aerosol models required for this analysis. The leading author thanks members of the NASA AATS and 4STAR teams for making valuable airborne measurements during different field campaigns, which served as a validation database for accessing the satellite-retrieved above-cloud AOD.

Edited by: A. Kokhanovsky

Reviewed by: A. M. Sayer and three anonymous referees

\section{References}

Chand, D., Anderson, T. L., Wood, R., Charlson, R. J., Hu, Y., Liu, Z., and Vaughan, M.: Quantifying above-cloud aerosol using spaceborne lidar for improved understanding of cloudysky direct climate forcing, J. Geophys. Res., 113, D13206, doi:10.1029/2007JD009433, 2008.
Chand, D., Wood, R., Anderson, T. L., Satheesh, S. K., and Charlson, R. J.: Satellite-derived direct radiative effect of aerosols dependent on cloud cover, Nat. Geosci., 2, 181-184, doi:10.1038/NGEO437, 2009.

Dunagan, S., Johnson, R., Zavaleta, J., Russell, P., Schmid, B., Flynn, C., Redemann, J., Shinozuka, Y., Livingston, J., and Segal-Rosenhaimer, M.: Spectrometer for Sky-Scanning SunTracking Atmospheric Research (4STAR): Instrument Technology, Remote Sens., 5, 3872-3895, doi:10.3390/rs5083872, 2013.

Eck, T. F., Holben, B. N., Reid, J. S., Mukelabai, M. M., Piketh, S. J., Torres, O., Jethva, H. T., Hyer, E. J., Ward, D. E., Dubovik, O., Sinyuk, A., Schafer, J. S., Giles, D. M., Sorokin, M., Smirnov, A., and Slutsker, I.: A seasonal trend of single scattering albedo in southern African biomass-burning particles: Implications for satellite products and estimates of emissions for the world's largest biomass-burning source, J. Geophys. Res.- Atmos., 118, 6414-6432, doi:10.1002/jgrd.50500, 2013.

Haywood, J. M., Osborne, S. R., Francis, P. N., Keil, A., Formenti, P., Andreae, M. O., and Kaye, P. H.: The mean physical and optical properties of regional haze dominated by biomass burning aerosol measured from the C-130 aircraft during SAFARI 2000, J. Geophys. Res.-Atmos., 108, 8473, doi:10.1029/2002JD002226, 2003.

Hu, Y., Vaughan, M., Liu, Z., Powell, K., and Rodier, S.: Retrieving optical depths and lidar ratios for transparent layers above opaque water clouds from CALIPSO lidar measurements, IEEE T. Geosci. Remote, 4, 523-526, doi:10.1109/LGRS.2007.901085, 2007.

Ichoku, C., Chu, D. A., Mattoo, S., Kaufman, Y. J., Remer, L. A., Tanré, D., Slutsker, I., and Holben, B. N.: A spatio-temporal approach for global validation and analysis of MODIS aerosol products, Geophys. Res. Lett., 29, doi:10.1029/2001GL013206, 2002.

Jethva, H., Torres, O., Remer, L., and Bhartia, P.: A Color Ratio Method for Simultaneous Retrieval of Aerosol and Cloud Optical Thickness of Above-Cloud Absorbing Aerosols From Passive Sensors: Application to MODIS Measurements, IEEE T. Geosci. Remote, 51, 3862-3870, doi:10.1109/TGRS.2012.2230008, 2013.

Jethva, H., Torres, O., Waquet, F., Chand, D., and Hu, Y.: How do A-train sensors intercompare in the retrieval of above-cloud aerosol optical depth? A case study-based assessment, Geophys. Res. Lett., 41, 186-192, doi:10.1002/2013GL058405, 2014.

Kacenelenbogen, M., Redemann, J., Vaughan, M. A., Omar, A. H., Russell, P. B., Burton, S., Rogers, R. R., Ferrare, R. A., and Hostetler, C. A.: An evaluation of CALIOP/CALIPSO's aerosol-above-cloud detection and retrieval capability over North America, J. Geophys. Res.-Atmos., 119, 230-244, doi:10.1002/2013JD020178, 2014.

Keil, A. and Haywood, J. M.: Solar radiative forcing by biomass burning aerosol particles during SAFARI2000: A case study based on measured aerosol and cloud properties, J. Geophys. Res., 108, 8467, doi:10.1029/2002JD002315, 2003.

Levy, R. C., Remer, L. A., and Dubovik, O.: Global aerosol optical properties and application to Moderate Resolution Imaging Spectroradiometer aerosol retrieval over land, J. Geophys. Res.Atmos., 112, D13210, doi:10.1029/2006JD007815, 2007.

Menzel, W. P., Frey, R. A., Zhang, H., Wylie, D. P., Moeller, C. C., Holz, R. E., Maddux, B., Baum, B. A., Strabala, K. I., and Gum- 
ley, L. E.: MODIS global cloud-top pressure and amount estimation: Algorithm description and results, J. Appl. Meteor. Climatol., 47, 1175-1198, doi:10.1175/2007JAMC1705.1, 2008.

Meyer, K., Platnick, S., Oreopoulos, L., and Lee, D.: Estimating the direct radiative effect of absorbing aerosols overlying marine boundary layer clouds in the southeast Atlantic using MODIS and CALIOP, J. Geophys. Res.-Atmos., 118, 48014815, doi:10.1002/jgrd.50449, 2013.

Meyer, K., Platnick, S., and Zhang, Z.: Simultaneously inferring above-cloud absorbing aerosol optical thickness and underlying liquid phase cloud optical and microphysical properties using MODIS, J. Geophys. Res.-Atmos., 120, 5524-5547, doi:10.1002/2015JD023128, 2015.

Peers, F., Waquet, F., Cornet, C., Dubuisson, P., Ducos, F., Goloub, P., Szczap, F., Tanré, D., and Thieuleux, F.: Absorption of aerosols above clouds from POLDER/PARASOL measurements and estimation of their direct radiative effect, Atmos. Chem. Phys., 15, 4179-4196, doi:10.5194/acp-15-4179-2015, 2015.

Redemann, J., Schmid, B., Eilers, J. A., Kahn, R., Levy, R. C., Russell, P. B., Livingston, J. M., Hobb Jr., P. V., W. L. S., and Holben, B. N.: Suborbital measurements of spectral aerosol optical depth and its variability at sub-satellite grid scales in support of CLAMS, 2001, J. Atmos. Sci., 62, 993-1007, doi:10.1175/JAS3387.1, 2001.

Redemann, J. S., Masonis, S. J., Schmid, B., Anderson, T. L., Russell, P. B., Livingston, J. M., Dubovik, O., and Clarke, A. D.: Clear-column closure studies of aerosols and water vapor aboard the NCAR C-130 during ACE-Asia, 2001, J. Geophys. Res., 108, 8655, doi:8610.1029/2003JD003442, 2003.

Russell, P. B., Livingston, J. M., Dutton, E. G., Pueschel, R. F., Reagan, J. A., DeFoor, T. E., Box, M. A., Allen, D., Pilewskie, P., Herman, B. M., Kinne, S. A., and Hofmann, D. J.: Pinatubo and pre-Pinatubo optical-depth spectra: Mauna Loa measurements, comparisons, inferred particle size distributions, radiative effects, and relationship to lidar data, J. Geophys. Res., 98, 22969-22985, doi:10.1029/93JD02308, 1993.

Sayer, A. M., Hsu, N. C., Bettenhausen, C., Lee, J., Redemann, J., Schmid, B., and Shinozuka, Y.: Extending "Deep Blue" aerosol retrieval coverage to cases of absorbing aerosols above clouds: Sensitivity analysis and first case studies, J. Geophys. Res.Atmos., 121, 4830-4854, doi:10.1002/2015JD024729, 2016.

Schmid, B., Hegg, D. A., Wang, J., Bates, D., Redemann, J., Russell, P. B., Livingston, J. M., Jonsson, H. H., Welton, E. J., Seinfeld, J. H., Flagan, R. C., Covert, D. S., Dubovik, O., and Jefferson, A.: Column closure studies of lower tropospheric aerosol and water vapor during ACE-Asia using airborne Sun photometer and airborne in situ and ship-based lidar measurements, J. Geophys. Res., 108, 8656, doi:10.1029/2002JD003361, 2003a.

Schmid, B., Redemann, J., Russell, P. B., Hobbs, P. V., Hlavka, D. L., McGill, M. J., Holben, B. N., Welton, E. J., Campbell, J. R., Torres, O., Kahn, R. A., Diner, D. J., Helmlinger, M. C., Chu, D. A., Robles-Gonzalez, C., and de Leeuw, G.: Coordinated airborne, spaceborne, and ground-based measurements of massive thick aerosol layers during the dry season in southern Africa, J. Geophys. Res., 108, 8496, doi:10.1029/2002JD002297, 2003b.
Segal-Rosenheimer, M., Russell, P. B., Schmid, B., Redemann, J., Livingston, J. M., Flynn, C. J., Johnson, R. R., Dunagan, S. E., Shinozuka, Y., Herman, J., Cede, A., Abuhassan, N., Comstock, J. M., Hubbe, J. M., Zelenyuk, A., and Wilson, J.: Tracking elevated pollution layers with a newly developed hyperspectral Sun/Sky spectrometer (4STAR): Results from the TCAP 2012 and 2013 campaigns, J. Geophys. Res.-Atmos., 119, 2611-2628, doi:10.1002/2013jd020884, 2014.

Shinozuka, Y., Johnson, R. R., Flynn, C. J., Russell, P. B., Schmid, B., Redemann, J., Dunagan, S. E., Kluzek, C. D., Hubbe, J. M., Segal-Rosenheimer, M., Livingston, J. M., Eck, T. F., Wagener, R., Gregory, L., Chand, D., Berg, L. K., Rogers, R. R., Ferrare, R. A., Hair, J. W., Hostetler, C. A., and Burton, S. P.: Hyperspectral aerosol optical depths from TCAP flights, J. Geophys. Res.Atmos., 118, 12180-12194, doi:10.1002/2013JD020596, 2013.

Spurr, R. J. D.: VLIDORT: A linearized pseudo-spherical vector discrete ordinate radiative transfer code for forward model and retrieval studies in multilayer multiple scattering media, J. Quant. Spectrosc. Ra., 102, 316-342, doi:10.1016/j.jqsrt.2006.05.005, 2006.

Stocker, T., Qin, D., Plattner, G.-K., Tignor, M., Allen, S., Boschung, J., Nauels, A., Xia, Y., Bex, V., and Midgley, P. (Eds.): IPCC, 2013: Climate Change 2013: The Physical Science Basis, Contribution of Working Group I to the Fifth Assessment Report of the Intergovernmental Panel on Climate Change, Cambridge University Press, Cambridge, United Kingdom and New York, NY, USA, 2013.

Torres, O., Jethva, H., and Bhartia, P. K.: Retrieval of Aerosol Optical Depth above Clouds from OMI Observations: Sensitivity Analysis and Case Studies, J. Atmos. Sci., 69, 1037-1053, doi:10.1175/JAS-D-11-0130.1, 2012.

Waquet, F., Riedi, J., Labonnote, L. C., Goloub, P., Cairns, B., Deuzeand, J.-L., and Tanre, D.: Aerosol Remote Sensing over Clouds Using A-Train Observations, J. Atmos. Sci., 66, 24682480, doi:10.1175/2009JAS3026.1, 2009.

Waquet, F., Cornet, C., Deuzé, J.-L., Dubovik, O., Ducos, F., Goloub, P., Herman, M., Lapyonok, T., Labonnote, L. C., Riedi, J., Tanré, D., Thieuleux, F., and Vanbauce, C.: Retrieval of aerosol microphysical and optical properties above liquid clouds from POLDER/PARASOL polarization measurements, Atmos. Meas. Tech., 6, 991-1016, doi:10.5194/amt-6-991-2013, 2013.

Wilcox, E. M., Harshvardhan, and Platnick, S.: Estimate of the impact of absorbing aerosol over cloud on the MODIS retrievals of cloud optical thickness and effective radius using two independent retrievals of liquid water path, J. Geophys. Res., 114, D05210, doi:10.1029/2008JD010589, 2009. 